\title{
A construção da escrita em crianças com síndrome de Down incluídas em escolas regulares
}

\author{
Ana Aparecida de Oliveira Machado Barby* \\ Sandra Regina Kirchner Guimarães** \\ Carla Luciane Blum Vestena ${ }^{* *}$
}

\section{Resumo}

O presente trabalho teve como objetivo investigar o desempenho na produção escrita de 4 crianças com Síndrome de Down, inseridas em classes regulares do ensino fundamental no município de Guarapuava, PR. Como procedimento, coletou-se 2 amostras de escrita de cada um dos participantes em dois momentos diferentes do ano letivo. A prova de escrita aplicada foi constituída de 4 palavras isoladas e uma frase e a análise do desempenho dos participantes foi fundamentada na psicogênese da língua escrita. Os resultados mostraram que as produçóes escritas das crianças com Síndrome de Down acompanhadas neste estudo foram semelhantes às descritas na literatura para seus pares. Porém, a evolução verificada ao longo do ano letivo foi lenta, mostrando que o processo de alfabetização dessas crianças demanda mais tempo. Concluiu-se que entre os alunos com Síndrome de Down, a aprendizagem da escrita acontece de forma semelhante a das demais crianças embora seja mais lenta. Assim, para garantir o processo de aprendizagem das crianças com Síndrome de Down sugerem-se adequaçôes nos planos de ensino e no tempo estipulado pelos programas escolares convencionais.

Palavras-chave: Síndrome de Down; Alfabetização; Inclusão.

* Professora Doutora da Universidade Estadual do Centro-Oeste, Guarapava, Paraná, Brasil.

** Professora Doutora da Universidade Federal do Paraná, Curitiba, Paraná, Brasil.

*** Professora Doutora da Universidade Estadual do Centro-Oeste, Guarapava, Paraná, Brasil. 


\section{The construction of writing in children with down's syndrome in conventional schools}

\section{Abstract}

Current research investigates performance in the writing production of four children with Down's syndrome in regular classes of the primary school in Guarapuava, Pr., Brazil. Two written samples from each participating child at two different instances during the scholastic year were collected. Written test comprised four separate words and a clause. The children's performance analysis was foregrounded on the psychogenesis of the writing language. Results showed that written products by children with Down's syndrome involved in current research were similar to those described in the literature for their peers. Development throughout the year was slow and showed that the children's schooling process demanded more time. In the case of children with Down's syndrome, learning to write is similar to the process of other children, albeit slower. So that the learning process by children with Down's syndrome may be guaranteed, adaptations in teaching planning and time stipulated by conventional school programs should be made.

Keywords: Down's syndrome; Reading and writing; Inclusion.

\section{Introdução}

Em virtude das mudanças ocorridas nas políticas públicas nas últimas décadas e das manifestaçóes do movimento pela educação inclusiva, houve um crescimento significativo no número de crianças com deficiências incluídas em classes regulares nos anos iniciais do Ensino Fundamental público, no Brasil. As matrículas neste segmento da educaçáo aumentaram de 239.506 em 2007, para 437.132 no ano de 2011 (MEC/INEP/CENSO, 2011).

Em consonância com a realidade nacional, no município de Guarapuava-PR, é cada vez mais frequente a inclusão de alunos com deficiência nos anos iniciais do Ensino Fundamental, entretanto, nesta regiáo são raros os estudos que investigam a aprendizagem escolar deste alunado. Segundo Bueno (2008) as pesquisas realizadas no Brasil sobre o desempenho escolar de alunos com deficiência intelectual atendidos na educação inclusiva e especial ainda são poucas e recentes.

Diante deste cenário criou-se o Laboratório de Educação Especial (LEE) da Universidade Estadual do Centro-Oeste (UNICENTRO), no Campus Santa Cruz, em 2009, com o objetivo desenvolver projetos de pesquisa, ensino e extensão junto a alunos com deficiências matriculados nos anos iniciais no município de Guarapuava-Pr.

Entre as crianças participantes do LEE encontram-se as que apresentam Síndrome de Down (SD), uma anomalia genética caracterizada por uma trissomia no par de cromossomos 21 que atinge cerca de 1 criança entre 600 e 700 nascidas vivas, e está associada à deficiência intelectual. Algumas características desta síndrome 
foram estudadas por Jean Esquirol em 1838 e Edouard Séguin em 1846, porém, foi John Langdon Down que em 1866 publicou um trabalho com a descrição sistematizada das características da Síndrome de Down, que levou seu nome. (PUESCHEL, 2005)

No Brasil, a escolarização dos alunos com SD teve início com a fundação de instituiçóes especializadas nas décadas de 1950/1960, e Freitas (2008, p. 59) alerta que o modelo de atendimento adotado era o médico-psicológico que se pautava na "reabilitação" e no "treino de habilidades". Mais recentemente, o movimento pró-inclusão respaldado pelas políticas públicas tem estimulado a promoção de sistemas de ensino inclusivos para os alunos com SD. (KASSAR, 2011)

Assim, a partir do final da década de 1990, estudos nacionais e estrangeiros têm se preocupado em investigar a aprendizagem da linguagem escrita nestes alunos e os resultados obtidos revelaram que as crianças e jovens com SD submetidos a programas de alfabetização desenvolvem algum nível de leitura (CARDOSO-MARTINS; FRITH, 1999; SÁS, 2009; BURGOYNE, 2012, BARBY, 2013) e de escrita (SALINAS; SANTANA, 2003; LAVRA-PINTO, 2009).

Destaca-se que tais estudos concentraram-se em investigar implicações das habilidades metalinguísticas na aprendizagem da linguagem escrita nos alunos com SD, sendo a consciência fonológica ou a capacidade de identificar e manipular consciente e intencionalmente os menores componentes sonoros da linguagem oral, a mais estudada. (LEMONS; FUCHS, 2010)

Segundo Lemons e Fuchs (2010) o início dos estudos sobre as relaçôes entre desenvolvimento da consciência fonológica e a aprendizagem da leitura em crianças com SD se deu com a publicação do estudo de Cossu, Rossini e Marshall (1993) afirmando que a consciência fonológica não é um pré-requisito para todas as crianças aprenderem a ler. Estes autores compararam o desempenho de um grupo de crianças italianas com SD em quatro provas de consciência fonológica, a outro com desenvolvimento típico. As crianças com SD tiveram desempenho significativamente apesar de apresentarem o mesmo nível de leitura que seus pares.

As conclusóes de Cossu, Rossini e Marshall (1993) originaram uma série de estudos estrangeiros, (CUPPLES; IACONO, 2000; GOMBERT, 2002; VERUCCI et al., 2006; BURGOYNE, et al. 2012; HULME et al., 2012) e nacionais, (CARDOSO-MARTINS; FRITH, 1999; MOUSSATCHÉ, 2002; CARDOSO-MARTINS; MICHALICK; POLLO, 2006; CARDOSO-MARTINS; SILVA, 2008; SÁS, 2009; LAVRA-PINTO; LAMPRECHT, 2010; BARBY, 2013), sobre as relaçôes entre a aquisição da leitura a consciência fonológica em indivíduos com SD. Lemons e Fuchs (2010) encontraram evidências da existência de relaçôes positivas entre consciência fonológica e leitura na população com SD em 20 estudos publicados em língua inglesa.

A aprendizagem da leitura, assim como da escrita demanda de uma intervenção direta, intencional e sistematizada, diferentemente da linguagem oral que ocorre de forma mais espontânea. Ou seja, muito embora a criança imersa em um meio 
cultural letrado desde muito cedo formule hipóteses sobre as formas de registro escrito, ela necessita do ensino do código alfabético e das regras formais que orientam o registro da linguagem oral.

Porém, o desenvolvimento da escrita nos alunos com SD, foi pouco estudado no Brasil e em geral integra um rol de elementos de análise elencados em trabalhos sobre a consciência fonológica e a leitura. Moussatché (2002); Lara, Trindade e Nemr (2007); Lavra-Pinto, Lamprecht (2010); Sás (2009) empregaram a teoria psicogenética de Ferreiro e Teberosky (1999) na interpretação e classificação das escritas recolhidas, utilizando estas informaçôes como referência na análise do desempenho dos participantes com SD em tarefas de consciência fonológica.

Os resultados obtidos pelo estudo realizado por Comin e Costa (2012) confirmam esta realidade. As autoras conduziram uma busca no Scielo, entre os anos de 2001 e 2011, por meio do termo 'Síndrome de Down escrita', e encontraram apenas quatro artigos. Uma nova consulta realizada a partir dos termos "Síndrome de Down leitura", "Síndrome de Down escrita" e "Síndrome de Down alfabetização", no mesmo período, possibilitou a identificaçáo de sete artigos.

Dentre os artigos localizados por Comin e Costa (2012), dois concentraramse em analisar aspectos relacionados à atenção e desempenho grafo-motor, e o perfil cinestésico-corporal na SD, e os outros dois investigaram as relaçóes entre o desempenho em tarefas de consciência fonológica e as hipóteses de escrita das crianças com SD baseados nas fases de construção da escrita de Ferreiro e Teberosky (1999).

Além dos estudos citados por Comin e Costa (2012), também merecem destaque o subprojeto de pesquisa de RANGEL (2006) que coletou amostras de escrita, ao longo de 1 ano, de uma aluna brasileira com SD de 9 anos que cursava o $2^{\circ}$ ano primário e as analisou à luz da teoria psicogenética de Ferreiro e Teberosky (1999). E de Salinas e Santana (2003) que estudaram a escrita de 17 crianças mexicanas com SD utilizando o mesmo referencial teórico (1999) para analisar e classificar as escritas coletadas. Já o estudo realizado por Barby (2013) sobre a consciência fonológica e apropriação da linguagem escrita em alunos com SD baseou-se na teoria de fases de Ehri (2013) para classificar e analisar a aprendizagem da escrita nesta população.

No que se refere às pesquisas sobre alfabetização, desenvolvidas a partir da concepção construtivista, consideram que a construção da escrita, na criança, resulta de um processo de proposição de hipóteses determinado por mudanças de nível conceitual. Os trabalhos de Ferreiro e Teberosky (1999) representam esta concepçáo no Brasil.

De acordo com a psicogênese da língua escrita (FERREIRO; TEBEROSKY, 1999), no esforço para compreender o funcionamento da língua escrita as crianças elaboram hipóteses que evoluem regularmente e podem ser descritas em diferentes níveis de desenvolvimento conceitual. No nível pré-silábico a criança descobre a natureza simbólica da escrita, mas não compreende que ela representa a fala, tenta imitá-la e agrega características reais dos objetos às suas representaçôes. A partir da convivência com a linguagem escrita a criança passa a trabalhar com dois princípios 
fundamentais deste período: o de que para escrever é preciso variar as letras (variações qualitativas) e o de que é preciso contar com um número mínimo entre 2 a 4 letras (quantidade mínima).

No nível silábico a criança passa por uma revolução conceitual ao perceber que a escrita representa a fala, porém, como não consegue detectar todos os sons individualmente na pronúncia e acredita que as letras representam sílabas. Em contato com a forma convencional da escrita apresentada pelo cotidiano escolar a criança contesta a escrita silábica e passa a representar componentes sonoros menores que a sílaba, atingindo o estágio silábico-alfabético. Finalmente a criança alcança o estágio alfabético quando passa a realizar a análise dos segmentos sonoros e estabelecer relaçôes mais claras entre grafemas e fonemas. (FERREIRO; TEBEROSKY, 1999)

Destaca-se que de acordo com Zorzi (1998) para escrever de forma convencional a criança precisa ainda compreender as regras e normas que regem a escrita, próprias da fase ortográfica.

Assim, considerando a relevância da linguagem escrita para as sociedades modernas, a necessidade de se conhecer de forma mais específica a aquisição deste conhecimento por alunos com SD e a pequena produção nacional sobre o tema, este estudo tem como objetivo: conhecer a forma como os alunos com SD aprendem o sistema de escrita alfabética; investigar as hipóteses de escrita apresentadas por 4 alunos com SD incluídos em escolas convencionais de ensino fundamental, no município de Guarapuava-Pr; descrever as possíveis mudanças ocorridas na produção escrita, destes alunos, durante um ano letivo.

\section{Método}

Foram selecionados para participar desta pesquisa crianças com diagnóstico de Síndrome de Down, incluídas em classes comuns nos anos iniciais do Ensino Fundamental público em Guarapuava, Pr, inscritas em programas do LEE, com o consentimento dos pais ou responsáveis.

Atendendo aos critérios mencionados, foram selecionados 4 participantes, 2 do sexo masculino (João - 7a, 10m; Paulo - 8a, 6m) e 2 do feminino (Juliana - 12a, $5 \mathrm{~m}$; Mariana - 10a, 4m), sendo adotados nomes fictícios para preservar suas identidades.

Em relação ao tempo de escolaridade todos os participantes já haviam repetido algum ano escolar, sendo que, Juliana, Mariana e Paulo iniciaram o ensino fundamental no ano em que completariam 7 anos de idade e Joáo no ano que completaria 6 anos.

O presente projeto foi aprovado pelo Comitê de Ética em Pesquisa (COMEP) da UNICENTRO-PR, sob o número 0078.0.300.000-09, e os pais autorizaram a participação dos filhos mediante a assinatura do Termo de Consentimento Livre e Esclarecido (TCLE).

Em relação à obtenção dos dados as pesquisadoras coletaram amostras de escrita dos participantes no início (fevereiro) e final (novembro) do ano letivo de 2011, 
em sessōes individuais de 30 a 40 minutos, com o auxílio de um ditado de 4 palavras e 01 frase: Borboleta; Cavalo; Sapo; Rá; e O gato bebe leite.

Mediante a obtenção dos dados realizou-se a análise qualitativa utilizando-se como base teórica o desenvolvimento da língua escrita em aprendizes com desenvolvimento típico, conforme proposto por Ferreiro e Teberosky (1999).

\section{Resultados}

Nas figuras 1 e 2, apresenta-se a primeira e segunda amostra de escrita da aluna Mariana coletadas com um intervalo de 9 meses entre elas. A aluna Mariana está incluída em uma classe comum do segundo ano do Ensino Fundamental, onde frequenta regularmente as aulas no período da tarde. Pela manhá participa de 2 sessóes (1 hora) na sala de recursos e 1 sessáo de fonoaudiologia (30 min.) ao longo da semana.

Observa-se que na primeira amostra (fig.1) Mariana utilizou quantidade semelhante de letras para todas as palavras e frase, usando o limite do papel como elemento finalizador e repetiu parte das letras em todas as tentativas (escritas fixas e repertório fixo parcial). Entretanto, associou valor sonoro inicial na primeira e terceira palavras (borboleta e sapo), ela também grafou as letras GAO ao iniciar a escrita da frase "O gato bebe leite", indicando que começava a estabelecer relaçóes entre a pronúncia e a escrita.

Figura 1 - Primeira amostra de escrita da aluna Mariana - 10a, 4m

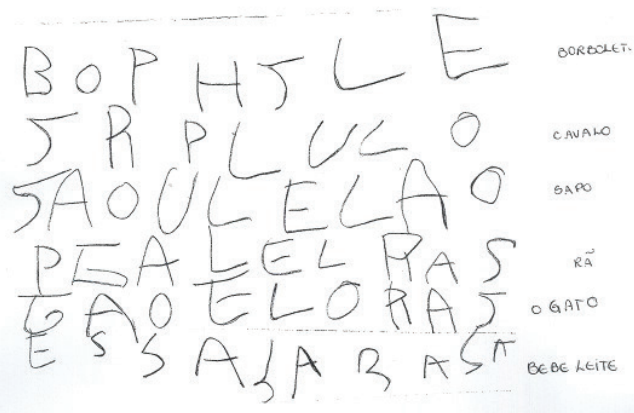

Na segunda amostra (Fig. 2), Mariana procurou diferenciar as palavras escritas, utilizando duas estratégias: a variaçáo quantitativa (número) e qualitativa (repertório) de letras, valendo-se das duas principais hipóteses do período pré-silábico, a de que para escrever é preciso um mínimo de letras $(2$ a 4$)$ e de variedade de caracteres (letras). (FERREIRO; TEBEROSKI, 1999). 
Figura 2 - Segunda amostra de escrita da aluna Mariana - 11a, $1 \mathrm{~m}$

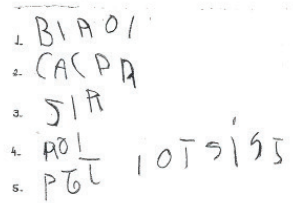

Destaca-se que, neste segundo momento, ao escrever as palavras isoladas a aluna grafou todas as letras iniciais de acordo com seu valor sonoro indicando a presença de diferenças qualitativas entre as duas amostras de escrita, apesar de ambas representarem o nível pré-silábico. Além disso, procurou apagar e reescrever várias letras nas palavras isoladas e na frase, demonstrando preocupação em relacionar a pronúncia com a escrita.

Nas figuras 3 e 4 apresenta-se a primeira e a segunda amostra de escrita do aluno João, também coletadas com um intervalo de 9 meses entre elas. João frequenta o segundo ano do Ensino Fundamental em classe comum, duas sessōes semanais na sala de recursos e uma de psicoterapia.

$\mathrm{Na}$ primeira amostra, nota-se que João utilizou a letra "A" (escrita unigráfica) e grafismos primitivos (sinais, traços) ligeiramente diferenciados para registrar as palavras e frase ditada. Com base nos estudos de Ferreiro e Teberosky (1999), a análise da escrita do João sugere que ele utilizou a estratégia de variar os sinais para lembrar mais tarde seus respectivos significados.

Figura 3 - Primeira amostra de escrita do aluno João - 7a, 10m 
Na segunda amostra, João utilizou novas letras, algumas com traços embaixo, e também teve a preocupaçáo de representar cada segmento da frase com uma letra. Demonstrando que apesar da sua escrita revelar características do nível pré-silábico ao final do ano, pode-se inferir que ele avançou na compreensão da natureza sonora da escrita, fato revelado pela segmentação da frase marcada pela repetição da letra "M". Porém, o fato do aluno ter iniciado o ano letivo desconhecendo os nomes e sons das letras, pode ter interferido na evolução e ritmo deste processo.

Figura 4 - Segunda amostra de escrita do aluno João - 8a, $7 \mathrm{~m}$

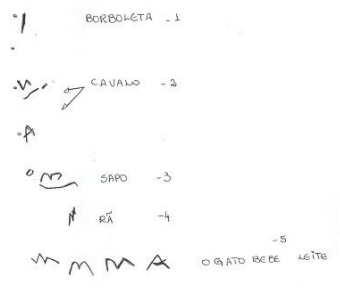

Nas Figuras 5 e 6, apresenta-se a primeira e segunda amostra de escrita do aluno Paulo. Este cursa o segundo ano do Ensino Fundamental em uma classe convencional e participa da sala de recursos duas vezes na semana, permanecendo uma hora em cada sessão.

Na primeira coleta (Figura 5), notou-se que Paulo fez uso de garatujas e mostrou-se bastante desatento, porém demonstrou diferenciar a escrita do desenho. Também teve dificuldades motoras no manuseio do lápis (força e apreensão) para efetuar os registros.

Figura 5 - Primeira amostra de escrita do aluno Paulo - 8a, 6m

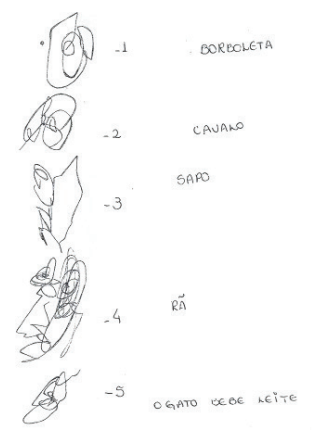


$\mathrm{Na}$ segunda amostra (Figura 6), Paulo representou as palavras por meio de grafismos primitivos (círculos) e mostrou-se mais preocupado e atento ao registrar cada uma delas.

Paulo apresentou melhoras na coordenação motora e manuseio do lápis, e demonstrou que percebia as palavras inteiras como unidades a serem registradas, porém como desconhecia as grafias, nomes e sons das letras durante as duas coletas, representando-as com círculos, mantendo-se no nível pré-silábico com grafismos primitivos.

Figura 6 - Segunda amostra de escrita do aluno Paulo - 9a, 3m

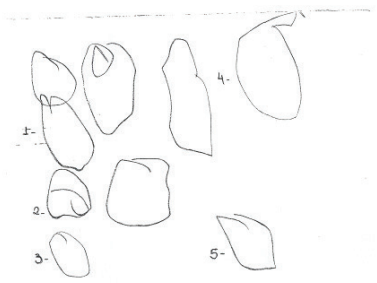

A seguir se apresenta as Figuras 7 e 8, respectivamente, referentes às amostras de escrita da aluna Juliana. Esta frequenta regularmente as aulas do quarto ano do Ensino Fundamental em uma classe convencional e, também participa da sala de recursos duas vezes na semana, permanecendo uma hora em cada sessão.

Ao analisar a primeira amostra (Figura 7) de escrita da Juliana, verifica-se que seu processo de construçáo da escrita mostra caraterísticas do nível silábico-alfabético, de acordo com a classificação proposta por Ferreiro e Teberosky (1999).

Figura 7 - Primeira amostra de escrita da aluna Juliana - 12a, 5m

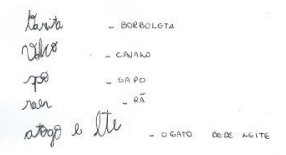


Na segunda amostra (Figura 8), notou-se um avanço no processo de aquisição da escrita da referida aluna, pois se aproximou ainda mais da escrita alfabética incluindo novas letras às palavras e segmentando melhor a frase, apesar de ainda apresentar omissóes e substituiçôes de letras.

Figura 8 - Segunda amostra de escrita da aluna Juliana - 13a, 2m

$$
\begin{aligned}
& \text { 1. Bate } \\
& \text { - Canver } \\
& \text { 3. Ge } \\
& \text { - ongate Bera elte }
\end{aligned}
$$

Observou-se ao longo da segunda sessão que Juliana parou várias vezes durante as tentativas de escrita, ora refletiu sobre o processo, ora questionou se estava certo o que havia escrito, demonstrando-se mais preocupada em escrever corretamente as palavras do que em fazer simples marcações para recordá-las mais tarde.

Ressalta-se ainda que, como já foi dito, Juliana frequenta o quarto ano do Ensino Fundamental e reconhece os nomes e sons de todas as letras do alfabeto, fazendo uso das letras de imprensa maiúscula e da manuscrita maiúscula e minúscula.

Por último, com o objetivo de sintetizar os dados obtidos neste estudo foi elaborado o quadro 1, que mostra o desempenho na escrita dos quatro participantes nos dois momentos da coleta de dados.

Quadro 1 - Desempenho relativo à escrita dos participantes no início e final do ano de 2011

\begin{tabular}{|c|c|c|c|c|c|c|c|c|}
\hline Participante & Idade & Ano & A & Borboleta & Cavalo & Sapo & Rã & $\begin{array}{c}\text { O gato bebe } \\
\text { leite }\end{array}$ \\
\hline \multirow{2}{*}{ Mariana } & \multirow{2}{*}{$10 \mathrm{a} 4 \mathrm{~m}$} & \multirow{2}{*}{$2^{\circ}$ ano } & $1^{\mathrm{a}}$ & BOPHSLE & SRPLULO & SAOULELAO & PGALELRAS & $\begin{array}{c}\text { GAOELORAS } \\
\text { ESSASARASA }\end{array}$ \\
\cline { 4 - 10 } & & $2^{\mathrm{a}}$ & BIPOI & CACPA & SIR & ROI & PGT IOTSIAS \\
\hline \multirow{2}{*}{ Paulo } & $8 \mathrm{a} 6 \mathrm{~m}$ & \multirow{2}{*}{$2^{\mathrm{o}}$ ano } & $1^{\mathrm{a}}$ & $\begin{array}{c}\text { Grafismo } \\
\text { primitivo }\end{array}$ & $\begin{array}{c}\text { Grafismo } \\
\text { primitivo }\end{array}$ & $\begin{array}{c}\text { Grafismo } \\
\text { primitivo }\end{array}$ & $\begin{array}{c}\text { Grafismo } \\
\text { primitivo }\end{array}$ & $\begin{array}{c}\text { Grafismo } \\
\text { primitivo }\end{array}$ \\
\cline { 4 - 9 } & $2^{\mathrm{a}}$ & Círculos & Círculos & Círculo & Círculo & Círculo \\
\hline
\end{tabular}


Continuação do Quadro 1

\begin{tabular}{|c|c|c|c|c|c|c|c|c|}
\hline \multirow{2}{*}{ Joáo } & \multirow{2}{*}{$7 \mathrm{a} 10 \mathrm{~m}$} & \multirow{2}{*}{$2^{\circ}$ ano } & $1^{\mathrm{a}}$ & A & $\begin{array}{l}\text { Grafismo } \\
\text { primitivo }\end{array}$ & $\begin{array}{l}\text { Grafismo } \\
\text { primitivo }\end{array}$ & $\begin{array}{l}\text { Grafismo } \\
\text { primitivo }\end{array}$ & $\begin{array}{l}\text { Grafismo } \\
\text { primitivo }\end{array}$ \\
\hline & & & $2^{\mathrm{a}}$ & I & $\begin{array}{l}\mathrm{N} \text { invertido } \\
\text { traço sob "A" }\end{array}$ & $\begin{array}{c}\text { O M traço } \\
\text { embaixo }\end{array}$ & $\mathrm{N}$ & M M M A \\
\hline \multirow{2}{*}{ Juliana } & \multirow{2}{*}{$12 \mathrm{a} 5 \mathrm{~m}$} & \multirow{2}{*}{$4^{\circ}$ ano } & $1^{\mathrm{a}}$ & Barita & Valco & Spo & Rar & atago e lte \\
\hline & & & $2^{a}$ & Bote & Cavlo & Spo (q) & Rar & o gato Bea elte \\
\hline
\end{tabular}

A análise deste conjunto de dados (quadro 1) revela diferenças e semelhanças relativas ao processo de construção da escrita, entre os alunos com Síndrome de Down incluídos nas classes regulares do Ensino Fundamental, participantes deste estudo.

No que se refere às diferenças observa-se que embora Mariana, Paulo e João frequentem o mesmo ano letivo e os três estejam no nível pré-silábico, todos apresentam diferenças qualitativas importantes na escrita, enquanto João e Paulo estão descobrindo os nomes das letras e representam as palavras por meio de escrita unigráficas e grafismos primitivos, Mariana testa suas hipóteses qualitativas e quantitativas utilizando diferentes combinaçôes de letras. Juliana venceu as etapas iniciais e se aproxima do nível alfabético ( $4^{\circ}$ ano). Vários fatores podem ter contribuído para estas diferenças, tais como, idade, tempo de escolarização, conhecimento das letras e método de ensino.

Quanto às semelhanças, observou-se que todos apresentaram evolução no desenvolvimento da escrita, cada um a seu modo e em seu tempo.

Destaca-se ainda que ao longo das sessóes as estratégias utilizadas pelos participantes para aprimorar as suas escritas, foram: repetiçáo das palavras em voz alta, perguntas sobre algumas letras e emprego de "marcas" para recordar o que havia sido registrado.

\section{Discussão}

Em âmbito geral, percebeu-se que o processo de desenvolvimento da escrita nos alunos com Síndrome de Down assemelha-se aos níveis descritos por Ferreiro e Teberosky (1999) para as demais crianças, diferenciando-se apenas no ritmo do processo, e na evidente necessidade de intervençôes específicas e pontuais para a elaboração de algumas noçóes básicas como as de espaço, tempo, causalidade e objeto. Noçôes estas elementares à construção das funçôes simbólicas (desenho, mapa mental, jogo simbólico, linguagem, etc), e essenciais ao desenvolvimento da leitura e escrita pelas crianças. Em outras palavras, é possível argumentar que não foram percebidas diferenças significativas de caráter qualitativo entre o processo de construção da escrita das crianças com desenvolvimento típico e o processo desenvolvido pelas crianças com Síndrome de Down.

Conclusão semelhante foi apresentada por Salinas e Santana (2003) ao investigarem um grupo de 17 alunos com SD, com idades entre 5 e 20 anos, que 
frequentavam classes regulares no México. As autoras utilizaram a classificação de Emília Ferreiro para analisar as produçôes escritas dos participantes e os resultados indicaram que as crianças com SD investigadas passaram pelas mesmas fases de desenvolvimento da escrita que as demais, porém, os progressos na aquisição da escrita foram registrados em crianças com idades mais avançadas.

A lentidão na aprendizagem da linguagem escrita na SD também foi observada por Hulme et al, (2012) ao investigarem a capacidade de leitura em 49 crianças com Síndrome de Down e compararam a 61 crianças com desenvolvimento típico, no Reino Unido. O estudo teve a duração de dois anos e os resultados mostraram que as crianças com SD apresentaram períodos de lentidáo na aprendizagem da leitura, fato que causou atrasos em comparação aos seus pares sem a Síndrome.

Outra dificuldade descrita por Buckley e Sacks (1987, apud TRANCOSO; CERRO, 2004) está relacionada ao uso efetivo da linguagem escrita por alunos com SD de forma independente, como uma ferramenta comunicativa. As autoras pesquisaram um grupo de 32 crianças e 34 adolescentes com SD, e apontam que a maioria conseguia copiar palavras e escrever seu nome, mas, apresentava dificuldades na escrita espontânea.

Estudos realizados por Inhelder e Piaget (1960) já haviam constatado a disparidade de tempo entre cada nível de construção da leitura e escrita, no que diz respeito aos aspectos cognitivos de crianças com e sem deficiência intelectual. Convém lembrar que estes estudos foram realizados com crianças que não frequentavam classes regulares de ensino em virtude de não existir, na época, uma política de inclusão.

A este respeito destaca-se que é preciso considerar a interferência de múltiplos aspectos de origem social, histórica e familiar, no processo e ritmo de aprendizagem da escrita nas crianças com SD. Piaget ao investigar crianças com desenvolvimento típico de diferentes regióes do planeta encontrou vários anos de diferença no desenvolvimento cognitivo entre elas. De fato, o que Piaget constatou foi que para explicar o processo de construção do conhecimento não apenas o aspecto biológico deve ser considerado, ou seja, sua tese é a de que há diferentes fatores que interferem neste processo, tanto no que se refere ao aspecto cognitivo do conhecimento, como também no âmbito social. Diante disso, é possível inferir que crianças com SD também estão sujeitas as interferências biológicas e sociais em seu desenvolvimento e aprendizagem escolar. (PIAGET, 1964)

No que se refere especificamente à aquisição da escrita nos participantes do presente estudo, destaca-se primeiramente a escrita de Mariana, que cursava na ocasião o segundo ano fundamental. Na primeira coleta de escrita, Mariana, utilizou-se da variação de letras para diferenciar as palavras e atribuiu valor sonoro inicial a algumas delas, porém repetiu grande parte das letras em todas as tentativas, mostrando um repertório pouco variado (fixo parcial), não se preocupando com a quantidade de letras. Na segunda amostra, Mariana avançou na estratégia pré-silábica de escrita, identificando o valor sonoro das letras iniciais das palavras, usando, "B" (borboleta), "CA" (cavalo), "S" (sapo), "R" (rã), mantém o princípio de variação de letras e pro- 
curou variar também o número de letras, mantendo um mínimo de três, utilizando conforme Ferreiro e Teberosky (1999) duas estratégias típicas do período pré-silábico. Apesar de Mariana não ter obtido um desempenho compatível com um nível mais evoluído de escrita, a vivência escolar neste intervalo de tempo, possibilitou uma evoluçáo qualitativa dentro do mesmo nível.

O aluno João também frequentou o segundo ano fundamental durante o ano da pesquisa e sua escrita permaneceu no nível pré-silábico, porém diferentemente de Mariana, mesmo no final do ano não conseguiu representar o valor sonoro das letras nas tentativas de escrita. Na primeira avaliação, João utilizou grafismos primitivos e a letra "A" para representar as palavras ditadas, e na segunda priorizou o emprego de escritas unigráficas (uma letra representando uma palavra). Entretanto, destaca-se que João mostrou uma evolução na compreensão da natureza da escrita, abandonando o uso de símbolos (predominante na primeira amostra) e priorizando o emprego de letras na segunda amostra. Também conseguiu segmentar a frase valendo-se da letra "M" para representar as palavras (uma letra para cada palavra).

Paulo também cursando o segundo ano fundamental utilizou-se de grafismos primitivos para representar as palavras e frase ditadas nas duas ocasióes em que foi avaliado. Durante as sessões registrava com sinais as palavras, mas depois não se recordava o que havia "escrito", não fornecendo indícios de que havia compreendido que a escrita representa o som das palavras faladas, mantendo-se estável nesta condição na segunda avaliação deste estudo quando usou o desenho celular.

Juliana ( $4^{\circ} \mathrm{ano}$ ), durante o intervalo de tempo do estudo, realizou conquistas no campo alfabético estabelecendo relações entre os sons e as letras individualmente, sobretudo nas palavras regulares onde cada grafema corresponde a apenas um fonema (cavalo, sapo, gato). Porém, não conseguiu distinguir e representar na escrita todos os sons da fala, omitindo ou trocando algumas letras, "BOTE - CAVLO - SPO - RAR BEA - ELTE”. Em síntese, na primeira avaliação deste estudo, Juliana conhecia todos os nomes e sons das letras, sendo que na segunda avaliaçáo (no final do ano) foi capaz de distinguir os sons da fala com mais precisão, o que ficou demonstrado pela sua capacidade de representar na escrita um número maior de fonemas.

Também Rangel (2006), Lara, Trindade e Nemr (2007), Lavra-Pinto e Lamprecht (2010) utilizaram a teoria psicogenética de Ferreiro e Teberosky (1999) para estabelecer e/ou analisar os níveis de escrita de crianças e jovens com SD em seus estudos sobre a consciência fonológica e aprendizagem da linguagem escrita.

\section{Considerações finais}

No início deste estudo, um dos objetivos propostos diz respeito à forma como os alunos com Síndrome de Down aprendem o sistema de escrita alfabética. Ao que foi possível observar que as crianças com Síndrome de Down participantes construíram conceitos e hipóteses sobre a linguagem escrita de forma semelhante às descritas por Ferreiro e Teberosky (1999), para as demais crianças, porém, mais tardiamente, conforme se observa pelas idades cronológicas dos participantes. Esses resultados corroboram com os achados de Salinas e Santana (2003); Lavra-Pinto e Lamprecht (2010), Hulme, et al (2012) Barby (2013). 
Outro dado importante revelado por este estudo foi que os participantes procuraram durante suas produções escritas desenvolverem estratégias para superar algumas dificuldades, consideradas comuns na Síndrome de Down, como limitações de memória de curto prazo, dificuldades no processamento auditivo e na coordenação motora fina. (PUESCHEL)

Quanto ao segundo objetivo, referente aos níveis de construção da escrita apresentados pelos alunos com Síndrome de Down e as mudanças ocorridas no seu desempenho depois de decorrido um ano letivo, verificou-se que as características de 3 participantes eram do mesmo nível (pré-silábico ) no início e final do ano. Entretanto, destaca-se que as estratégias de escrita utilizadas por estes foram diferenciadas (grafismos primitivos, escritas unigráficas, fixas ou com repertório e quantidade variados). Uma participante apresentou variaçóes que se aproximaram do estágio alfabético.

Com relação ao terceiro objetivo aqui proposto, pode-se dizer que ocorreram mudanças qualitativas (dentro do mesmo nível) na escrita de todos os participantes, fato evidenciado no momento da segunda amostragem quando todas as crianças identificaram suas representaçôes gráficas como escritas, "marcas" que serviam para ler, indicando compreensão da natureza da escrita, muito embora, João e Paulo não tenham conseguido "ler" o que haviam escrito.

Portanto, as escritas coletadas evidenciaram que todas as crianças investigadas, apresentaram evolução na construção do sistema de representação gráfica, ao longo de um ano letivo, obviamente cada uma em seu ritmo e a seu modo. Assim, parece evidente o potencial evolutivo de todas as crianças, porém sugere-se a necessidade dos educadores encontrarem formas de intervenção pedagógica que proporcionem maior agilidade na construçáo do sistema de escrita e no aperfeiçoamento deste processo. Dito de outro modo, o tempo escolar (os anos previstos no ensino regular) não pode ser um obstáculo para as aprendizagens das crianças com SD, por isso faz-se necessárias adaptaçôes curriculares para atender as necessidades destas crianças.

Destaca-se que este estudo deteve-se à análise das manifestaçôes escritas apresentadas por alunos com SD ao longo de um ano letivo por meio da coleta de amostras de escrita, não aprofundando a análise dos múltiplos fatores que podem ter interferido no ritmo e qualidade da construção deste processo. Também não foi aplicado nenhum programa de intervenção para avaliar as diferentes variáveis que compóem a aprendizagem da leitura e escrita. Do mesmo modo que não se investigou as questóes semânticas da escrita destas crianças.

\section{Referências}

BARBY, A. A. O. M. Desenvolvimento de habilidades metafonológicas e aprendizagem da leitura e escrita em alunos com Síndrome de Down. [Tese de Doutorado], Curitiba: UFPR, 2013.

BURGOYNE, K.; DUFF,F., J.; CLARKE, P., J.; BUCKLEY, S.; SNOWLING, M., J.; HULME, C. Efficacy of a reading and language intervention for children with Down Syndrome: a randomized controlled trial. The Journal of Child Psychology and Psychiatry. 2012; 53(10): 1044-1053.

CARDOSO-MARTINS, C.; SILVA, J. R. A relação entre o processamento fonológico e a habilidade de leitura: evidência da Síndrome de Down e da Síndrome de Williams. Psicologia: Reflexão \& Crítica. 2008; 21(1): 151-159. 
CARDOSO-MARTINS, C.; FRITH, U. Consciência fonológica e habilidade de leitura na síndrome de Down. Psicologia: Reflexão \& Crítica. 1999; 12(1): 209-224.

CARDOSO-MARTINS, C.; MICHALICK, M.; POLLO, T. O papel do conhecimento do nome das letras no início da aprendizagem da leitura: evidência de indivíduos com síndrome de Down. Psicologia: Reflexão \& Crítica. 2006; 19(1): 53-59.

COSSU, G.; ROSSINI, F.; MARSHALL, C. When reading is acquired but phonemic awareness is not: a study of literacy in Down's syndrome. Cognition. 1993; 46: 129-38.

COMIN, B. C.; COSTA, M. P. R. Síndrome de Down: análise dos artigos sobre leitura, escrita e alfabetizaçâo de 2001 a 2011. Revista Eletrônica de Educaçáo. São Carlos, SP: UFSCar; 6(2): 321-339.

CUPPLES, L. \& IACONO, T. Phonological awareness and oral reading skill in children with Down syndrome. Journal of Speech, Language, and Hearing Research. 2000; 43: 595-608.

EHRI, L. O desenvolvimento da leitura imediata de palavras: fases e estudos. In: SNOWLING, M. J.; HULME, C. (Orgs.). A ciência da leitura. Tradução: Ronaldo Cataldo Costa. Porto Alegre: Penso, 2013, 678 p. FERrEIRO, E.; TEBEROSKY, A. Psicogênese da língua escrita. Porto Alegre: Artmed, 1999.

HULME, C.; GOETZ, K.; BRIGSTOCKE, S.; NASH, H. M; LERVAG, A.; SNOWLING, M. J. The growth of reading skills in children with Down Syndrome. Developmental Science. 2012; 15(3): 320-329.

INHELDER, B. Le Diagnostic du raisonnement chez les débiles mentaux. Actualités Pedagogiques et Psychologiques. Troisième edition. Delachaux et Niestlé. Neuchatel, Suisse, 1969.

KASSAR, M. C. M. Percursos da constituição de uma política brasileira de educação especial inclusiva. Revista Brasileira de Educaçáo Especial. 2011; 17 (Ediçāo Especial): 41-57.

LARA, A. T. M. C.; TRINDADE, S. H. R.; NEMR, K. Desempenho de indivíduos com Síndrome de Down em testes de consciência fonológica aplicados com e sem apoio visual de figuras. Revista CEFAC. 2007; 9(2): 164-173.

LAVRA-PINTO, B.; LAMPRECHT, R. R. Consciência fonológica e habilidades de escrita em crianças com síndrome de Down. Pró-Fono. 2010 jul-set; 22(3):287-92.

LEMONS, C. J.; FUCHS, D. Phonological awareness of children with Down syndrome: Its role in learning to the read and the effectiveness of related interventions. Research in Developmental Disabilities. 2010; 31: 316-330.

MEC/INEP/CENSO. Ministério da Educaçáo, Instituto Nacional de Estudos e Pesquisas Educacionais Anísio Instituto Nacional de Estudos Teixeira. Disponível em: <http://portal.mec.gov.br/index.php?option=com_content\&view=article\&id=16179>. Acesso em: 19 fev. 2013.

MOUSSATCHÉ, A. H. Alfabetizaçáo e consciência fonológica: um estudo de intervenção com jovens pré -leitores portadores de síndrome de Down [Tese de Doutorado]. São Paulo: USP, 2002.

PIAGET, J. Development and Learning. Journal of Research in Science Teaching. 1964; 11(3) 176-186.

PUESCHEL, S. (org.). Síndrome de Down: guia para pais e educadores. Trad. Lucia Helena Reily. 12. ed., Campinas, São Paulo: Papirus, 2007.

RANGEL, G. A. Processo de aquisiçấo da escrita por crianças com Síndrome de Down. Pesquisa: Aquisiçáo da Escrita e Letramento: a linguagem e suas representaçōes nas relaçōes de pertencimento à escola. CNPq no 480865/2004-3, coord. ROSA, C. M. Disponível em: <http://www.celsul.org.br/Encontros/07/dir2/4.pdf>. Acesso em: 10 maio 2016.

SALINAS, E. M.; SANTANA, I. S. Las nociones de la lengua escrita em El alumno com síndrome de Down. Lectura y Vida. 2003; 24(3).

SÁS, R. M. Efeitos de um programa de remediaçăo fonológica nas habilidades de leitura e escrita em alunos com síndrome de Down [Dissertação de Mestrado]. São Carlos: UFSCAR, 2009.

TrOnCOSO, M. V.; CERRO, M. M. Síndroma de Down: leitura e escrita. Portugal: Porto Editora, 2004.

VERUCCI, L.; MENGHINI, D.; VICARI, S. Reading skills and phonological awareness acquisition in Down syndrome. Journal of Intellectual Disability Research. 2006; 50(7): 477-91.

ZORZI, J. L. Aprender a escrever: a apropriação do sistema ortográfico. Porto Alegre: Artes Médicas; 1998. 
Ana Aparecida de Oliveira Machado Barby - Sandra Regina Kirchner Guimarães - Carla Luciane Blum Vestena

\section{Correspondência}

Ana Aparecida de Oliveira Machado Barby - Universidade Estadual do Centro-Oeste, Campus de Guarapuava, Departamento de Educação. Rua Presidente Zacarias, 875, Santa Cruz. CEP: 85015-430 - Guarapuava, Paraná, Brasil.

E-mail: anambarby@hotmail.com - srkguimaraes@uol.com.br - clbvestena@gmail.com

Recebido em 13 de outubro de 2015

Aprovado em 11 de maio de 2016 